\title{
Intestinal Atresia
}

National Cancer Institute

\section{Source}

National Cancer Institute. Intestinal Atresia. NCI Thesaurus. Code C84790.

A congenital malformation characterized by the absence of a normal opening in a part of the intestine. It can occur either in the small or the large intestine. 